\title{
Tension-Type Headache in Children: The Cinderella of Headache Disorders!
}

\author{
Shashi S. Seshia, Ishaq Abu-Arafeh, Andrew D. Hershey
}

\begin{abstract}
Tension-type headache (TTH) may be as common a headache disorder as migraine in children and adolescents. TTH has a neurobiological basis with genetic and environmental factors making variable contributions to the different sub-types. The diagnostic criteria for TTH in the second edition of the "International Classification of Headache Disorders" appear to be applicable to children. Anxiety and mood disorders may be co-morbid with frequent episodic and chronic TTH. Psychosocial stressors play an important role in precipitating and maintaining TTH. Hence, a biopsychosocial approach should be adopted for care. Standardized histories and examinations together with prospective headache diaries are the foundations for good management; attention to 'red flags' will help identify secondary causes that present with headache similar to TT. There are no randomized controlled drug trials for the treatment of TTH. Relaxation and cognitive behavioral therapies are effective. TTH in children and adolescents warrants greater recognition from the clinician and scientist. Studies focusing on TTH are overdue.
\end{abstract}

RÉSUMÉ: Céphalée de tension chez les enfants : la Cendrillon des céphalées! La céphalée de tension (CT) est peut-être aussi fréquente que la migraine chez les enfants et les adolescents. La CT a un fondement neurobiologique, et des facteurs génétiques et environnementaux contribuent de façon variable à différents sous-types de CT. Le critère diagnostique de la CT dans le ICHD-II paraît applicable aux enfants. L'anxiété et les troubles de l'humeur peuvent être des entités co-morbides chez ceux qui présentent une CT épisodique et chronique fréquente. Les facteurs de stress psychosociaux jouent un rôle important dans son déclenchement et son entretien. Une approche biopsychosociale de soins doit donc être préconisée. La base d'une bonne prise en charge est l'histoire standardisée et l'examen ainsi qu'un journal prospectif des épisodes de céphalée en portant une attention particulière aux «drapeaux rouges » ce qui aidera à identifier les causes secondaires de céphalée dont la présentation est semblable à la CT. Il n'existe pas d'études de pharmacologie clinique contrôlées et randomisées dans le traitement de la CT. La relaxation et les thérapies comportementales cognitives sont efficaces. La CT chez les enfants et les adolescents mérite une plus grande reconnaissance de la part des cliniciens et des chercheurs. Des études sur ce sujet auraient dû être faites depuis longtemps.

Can. J. Neurol. Sci. 2009; 36: 687-695

Tension-Type Headache (TTH) is the most common primary headache in adults. ${ }^{1}$ In one study, the lifetime prevalence for migraine was $8 \%$ in men and $25 \%$ for women, while that for TTH was $69 \%$ and $88 \%$ respectively. $^{2}$ As a consequence, TTH has a greater personal and economic impact than migraine..$^{1,3}$ Despite its frequency and effect on individuals and society, TTH is a 'neglected headache disorder' that has 'to fight for its recognition' ${ }^{3,4}$ Relative to migraine, TTH is often overlooked by the clinician, neglected by the basic scientist and ignored by the pharmaceutical industry. ${ }^{4}$ Additionally, TTH is socially minimized because of the psychological overtones associated with the name. Tension-type headache in children (the term will be used to include adolescents) has suffered a similar fate and deserves to be rescued from the cellars of pediatric headache. This review is aimed at this end.

\section{Classification}

The sub-classification of TTH in the 2nd edition of the International Headache Society's 'The International Classification of Headache disorders' [ICHD-II] ${ }^{1}$ is an expansion of that in the first [ICHD I].${ }^{5}$ For the most part, the differences are not substantive. Table 1 is an abbreviated version. ${ }^{1}$ The differentiation between infrequent and frequent episodic tension-type headache (ETTH) is based on headache frequency, an arbitrary criterion, as the frequency can vary from one month to another in the same subject. A few studies have addressed the ICHD-I and II criteria for the diagnosis of TTH in children..$^{6-13}$ In the absence of a gold standard for diagnosis, there will be clinical ambiguity. ${ }^{13,14}$ The situation is also confounded by the inability of some children to be good historians. ${ }^{13-16}$ However, the general consensus in the literature suggests that the ICHD-II criteria for TTH are 'broadly' applicable to children. Further studies are needed to confirm the opinion.

From the Division of Pediatric Neurology, Department of Pediatrics (SSS), University of Saskatchewan, Saskatoon, SK, Canada; Paediatrics and Paediatric Neurology (IAA), Stirling Royal Infirmary, Stirling, UK; Headache Center, Cincinnati Children's Hospital Medical Center (ADH), Pediatrics and Neurology, University of Cincinnati, College of Medicine, Cincinnati, Ohio, USA.

Received April 2, 2009. Final Revisions Submitted June 18, 2009 Correspondence to: Shashi S. Seshia, 10 Stockton Place, Winnipeg, Manitoba, R3P 1X2, Canada. 
Table 1: Classification and criteria for TTH

\begin{tabular}{|c|c|c|c|}
\hline Diagnostic criteria & $\begin{array}{l}\text { Infrequent episodic } \\
\text { Code } 2.1\end{array}$ & $\begin{array}{l}\text { Frequent episodic } \\
\text { Code } 2.2\end{array}$ & $\begin{array}{l}\text { Chronic } \\
\text { Code } 2.3\end{array}$ \\
\hline A. Frequency & $\begin{array}{l}<1 \mathrm{day} / \text { month } \\
\geq 10 \text { episodes }\end{array}$ & $\begin{array}{l}1-15 \text { days/month } \\
\text { for } \geq 3 \text { months }\end{array}$ & $\begin{array}{l}\geq 15 \text { days/month } \\
\text { For }>3 \text { months }\end{array}$ \\
\hline B. Duration & 30 min-7 days & $30 \mathrm{~min}-7$ days & Hours-continuous \\
\hline \multicolumn{4}{|l|}{ C. At least 2 of: } \\
\hline Intensity & mild/moderate & $\operatorname{mild} /$ moderate & mild/moderate \\
\hline Location & bilateral & bilateral & bilateral \\
\hline Quality & Pressing/tightening & Pressing/tightening & Pressing/tightening \\
\hline Aggravated by activity & - & - & - \\
\hline \multicolumn{4}{|l|}{ D. Both of the following: } \\
\hline Nausea or vomiting & - & - & mild nausea \pm \\
\hline Photo- or phonophobia & + & + & + \\
\hline E. Attributed to other disorder & - & - & - \\
\hline
\end{tabular}

Note: This is an 'abbreviated' version from ICHD-II. ${ }^{1}$ Please consult the original for details and for information on sub-types (at the 3rd digit level) and of 'probable TTH' (code 2.4).

\section{Epidemiology}

Episodic and chronic $\boldsymbol{T T H}$ : The majority of population studies have been done in those of school age and older. Hence, epidemiological data on children under $<7$ years are inadequate. Prevalence rates for TTH vary from $10 \%$ to $72 \%$ in population studies likely because of differences in definitions, racial/ genetic background, environment, and methodology. ${ }^{9,17-23}$ The comparable prevalences for migraine were $11 \%, 11 \%$ and $21 \%$ for migraine and $25 \%, 10 \%$ and $5 \%$ for $\mathrm{TTH}$ respectively in three studies $;^{9,20,23}$ the prevalence of chronic TTH (CTTH) ranged from 0.1 to $5.9 \% .^{9,20,24}$ The relative frequencies for ETTH and CTTH in clinic based studies ranges from 16\%-20\% and $7 \%-22 \%$ respectively; so, at least one third of children attending specialist clinics with headache as their chief complaint had either ETTH or CTTH. 6,7,16,25 Tension-type headache was more frequent than migraine in $<6$ year olds, accounting for a third to almost half of cases in two clinic based studies. ${ }^{10,11}$ Thus, TTH occurs frequently enough in the pediatric age group to warrant greater attention.

Mixed migraine and TTH: Migraine and TTH often 'coexist' but the basis is still vigorously debated. The continuum ("lumper") model suggests that the types of headache, including $\mathrm{TTH}$, experienced by migraineurs, have the same underlying biological substrate i.e. migraine and TTH should be classified as migraine. ${ }^{26-28}$ The alternate dichotomous ("splitter") theory postulates that migraine and TTH are distinct entities. ${ }^{29}$ Both views, neither of them conclusively evidence based, discourage the concept of a 'mixed' category. Lipton et al felt that migraine and TTH were biologically distinct; at the same time they supported the continuum model 'among migraine sufferers' 30 Clinical data favor the existence of a 'mixed' ('overlap'; 'comorbid') group. The one year prevalence for mixed migraine and TTH was 6\% (90 of 1371 children) in the population based study of Laurell et al. ${ }^{20}$ Approximately one third of those presenting with recurrent headache to a specialist clinic had mixed migraine and TTH. ${ }^{25}$ There was a shift over time from migraine to TTH and vice-versa in about a quarter to a third of the study population in three clinic-based longitudinal studies. ${ }^{12,31,32}$ Chronic migraine and CTTH also co-exist with varying frequency (4\% to 53\%) in clinic-based studies. ${ }^{7,16,33}$ The interrelation between TTH and migraine is greater than can be attributed to chance. ${ }^{34}$ Chronic tension-type headache cooccurring with chronic migraine is assimilated within the concept of chronic migraine in the new appendix criteria for 'a broader concept of chronic migraine'; ${ }^{35}$ this is unfortunate as the possibility that the mixed category is genetically different from the 'pure' types needs to be explored. In some cases, migraine and TTH may share neurobiological mechanisms, ${ }^{4}$ providing a basis for their clinical association. The recognition of a mixed category has important implications for clinical trials and pharmacologic treatment.

\section{Genetics}

The high prevalence of infrequent and frequent ETTH makes it difficult to separate the effects of genetics from the chance occurrence of headache within family members. The reliance on subjective clinical opinions and the absence of a biological marker also pose challenges in assessing genetic contributions. Familial occurrence of TTH has been reported but a clear pattern of Mendelian inheritance has not been demonstrated. ${ }^{33,36}$

Twin studies on headache, although ideal, are difficult to compare, because of differences in methodology. Svensson et al found familial aggregation and suggested a significant role for genetic effects for TTH in eight to nine year old twins. ${ }^{37} \mathrm{~A}$ twin study in adults showed that environmental and chance occurrence contributed to $81 \%$ of the predisposition to episodic TTH with $19 \%$ attributed to genetic influences. ${ }^{38}$ Russell et al found that genetic factors contributed to almost half of the 
variance in the liability to TTH. ${ }^{39}$ Russell suggests that frequent episodic and CTTH are caused by a combination of genetic and environmental factors, while infrequent $\mathrm{TTH}$ is caused 'primarily' (but likely not exclusively) by environmental factors. ${ }^{40}$ CTTH has multifactorial inheritance making it challenging to identify genetic markers. ${ }^{40}$ Thus, there is some evidence for genetic susceptibility to frequent ETTH and CTTH but the relatively low contribution (19\%) argues for the environment playing a more significant role.

\section{Gender}

Boys and girls are equally affected till about 12 years-of-age, after which there is a female predominance. ${ }^{20,23}$ Possible explanations for the greater susceptibility of post-pubertal females to pain syndromes such as TTH include: (i) influence of gonadal hormones on pain processing, ${ }^{41}$ (ii) sex differences in processing pain and in mechanisms such as central and peripheral sensitization, ${ }^{42}$ and (iii) gender differences in cognitive and social reactions to pain, including desire to seek medical care for pain. ${ }^{43}$ These are important considerations in tailoring management.

\section{The Neurobiology of TTH (Figure)}

Several studies suggest a neurobiological basis for TTH in adults with both peripheral and central mechanisms involved..$^{3,42,44-47}$ In addition to the genetic and gender aspects discussed earlier, the authors outline other possible processes that include: (i) central mechanisms by which emotion, including stress, contribute to TTH; (ii) peripherally, striatal muscle and peripheral nerve sensitization, a variety of potential chemical mediators being involved; (iii) central factors contributing to abnormal pain sensitivity as demonstrated by generalized hyperalgesia in patients with $\mathrm{CTTH}$, suggesting abnormal central antinociceptive systems; (iv) abnormalities in biochemical mechanisms including central serotonin and endogenous endorphin systems and neuropeptides. The roles of various levels of the nervous system and of putative neurotransmitters and related neuromodulators [including nitric oxide, Calcitonin gene-related peptide, substance $\mathrm{P}$, neurokinin A, glutamate, serotonin, $\beta$-endorphin and met-enkaphalin etc] have been discussed in detail by Bendtsen ${ }^{45}$ and Vandenheede $\&$ Schoenen. ${ }^{46}$ All these factors are susceptible to genetic and epigenetic influences that could affect individual, familial and racial susceptibility. Although little or no research on children has been possible, it is likely that children and adults share similar pathophysiological processes. However, developmental aspects will have to be factored in. The neurobiological basis for TTH in children is uncharted territory urgently awaiting exploration.

\section{Associations (possibly co-morbid conditions)}

Anxiety and mood disorders are co-morbid with TTH, especially CTTH. 7,16,18,22,31,48 'Major' depression occurred in $1.5 \%$ and 'depressive symptoms' in $17 \%$ of 140912 year-old Finnish school children with ETTH. ${ }^{18}$ Additonal population based studies are needed to better define the prevalence of the association between anxiety disorders, mood disorders and the sub-types of TTH. Depression (and anxiety) enhances sensitivity to pain through central mechanisms and contributes to central sensitization and therefore $\mathrm{CTTH}^{3}{ }^{3}$

\section{Precipitating and contributory factors}

Positive psychosocial stressors such as excitement, parties and upcoming family holidays and negative life events, especially school related and family related, are the most important factors precipitating and contributing to TTH. ${ }^{7,10,11,16,18,22,32,33,49,50}$ Other factors include smells, lights, hunger, sleep deprivation, and noise. Stressful life events preceded or coincided with onset of CTTH in half of the patients in one study. ${ }^{7}$ Therefore, stressors should be considered as potential key causes of transformation from ETTH to CTTH. Stressors are often multiple.

Episodic tension-type headache may transform to CTTH through overuse of analgesics. ${ }^{1}$ In one clinic based study, five (4.3\%) of 115 children with almost daily headache were considered to have CTTH and analgesia-induced headache; ${ }^{7}$ in another study on chronic daily headache, of 12 children with CTTH one was associated with probable medication-overuse. ${ }^{33}$ We are not aware of any physiologically or pharmacologically based criteria for analgesia overuse in children. These need to be established to properly assess medication-overuse in TTH in children.

\section{Clinical Features (Table 1)}

Episodic tension-type headache generally starts in the afternoon at school. Often, the child can carry on with favorite activities despite severe or constant headache ('I forget my headache'). Unlike migraine, physical activity does not worsen TTH. Children with CTTH frequently have headache from the time they wake up to the time they go to bed; sleep is rarely disturbed. Headaches are rare or absent during extended holidays, a reason why clinical confirmation of the diagnosis may require assessment over such periods. Some with CTTH may be disabled. Hence, intensity of headache may be severe in children with TTH rather than the mild or moderate suggested in ICHD-II. ${ }^{1}$

\section{Rating disability and quality of life}

It is ideal to rate disability from TTH through a standardized questionnaire similar to PedMIDAS for migraine. ${ }^{51}$ The questions in PedMIDAS are not migraine specific. However, we cannot recommend PedMIDAS for use in TTH because TT headaches are generally less severe and disabling than migraine. Hence, the grading system for PedMIDAS may not be applicable for TTH. Universally acceptable quality of life measures in children to assess impact of all types of headache are needed. ${ }^{52,53}$

\section{History and physical examination}

History. There is no substitute for a full clinical history in order to optimize diagnosis and management. The use of standardized data sheets (example: www.bpna.org.uk; many headache clinics are happy to share their data collection forms) is recommended. Information to assist headache typing, identify causative/precipitating factors (example, concussion; stressors), recognize triggers (example, noise), identify other associated pain syndromes and diagnose mood and anxiety disorders can be 
captured. Family and social histories are essential components of pediatric practice. The family history must include information about headache (and type), anxiety, mood disorders and other pain syndromes especially in first and second degree relatives. Potential stressors should be reviewed systematically. Objective reports about school attendance and performance, participation in extra-curricular activities and life-style have to be obtained.

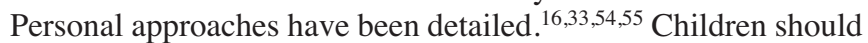
be allowed to use their own words in describing their symptoms. Families should be advised to keep detailed diaries prior to the first appointment so that prospective information is available to be reviewed time-effectively.

Physical Examination. A detailed examination of all systems, especially neurological, is essential. Important aspects of general examination include, the head circumference, height, weight (calculating body mass index), blood pressure, assessing for tenderness over sinuses/temporo-mandibular joints, muscles of the shoulder/neck cranium, and visual acuity. One should also assess for cough/valsalva maneuver induced headache.

\section{Table 2: Red flags}

Inadequate history (description of headache and related features)

Subject not co-operative (inability to do a complete neurological examination)

Age $<5$ years (relative red flag)

Short or ultra-short paroxysms of headache (these are uncommon in children)

Focal Neurological symptoms

Neurological symptoms or signs of raised or low intracranial pressure (example: headaches worsened with postural change)

Personality change

Deterioration of school work

Occipital location of headache

Headache worsened with coughing or physical activity

Headache awakening the child up from sleep or consistently occurring first thing in the morning

Associated symptoms in neck or back

Pre-existing hydrocephalus/shunt

Neurological signs

\section{Differential diagnosis}

The diagnosis of a primary headache disorder, such as ETTH or CTTH, requires exclusion of possible underlying organic disorders. Serious neurological disorders, although extremely uncommon, are of concern to parents and doctors. ${ }^{56}$ These can generally be excluded on the basis of the clinical history and neurological examination. ${ }^{56,57}$ The clinical features that should alert one to a potentially serious underlying disorder in children with TTH are listed in Table 2. Age $<5$ years is considered a red flag because: (i) brain tumors are relatively more common in the younger child than older; conversely, primary headache disorders are relatively less common, and (ii) young children are often unable to provide precise and detailed information about headache characteristics that help separate primary from secondary headache disorders.

Idiopathic intracranial hypertension and hypotension syndromes should be considered if position and postural changes influence headache. In children with hydrocephalus, ventriculoperitoneal shunt malfunction may present with headache that mimics TTH or migraine. ${ }^{58}$ Posttraumatic headache, especially following sports related concussions, are important causes of new onset ETTH or CTTH $;{ }^{59,60}$ the cause may be overlooked if such history is not sought. These are classified under code 5 (headache attributed to head and/or neck trauma) rather than code 2 (TTH) in ICHD-II. ${ }^{1}$

Children with TTH are often misdiagnosed as having sinusitis on the basis of incidental radiological findings. ${ }^{61}$ Headache due to sinusitis (rhinosinusitis as per ICHD-II, code $11.5^{1}$ ) is commonly dull, localized over the affected sinus and associated with local tenderness. Nasal obstruction, purulent discharge from the nostrils and fever may be present.

Impaired visual acuity may be associated with TT like headaches. ${ }^{58}$ Headache due to temporo-mandibular (TM) joint dysfunction (code 11.7; ICHD- $\mathrm{II}^{1}$ ) is rare in children; pain is precipitated by jaw movements or chewing. There may be reduced range of jaw opening, noise from one or both TM joints during jaw movements and tenderness of the joint capsule on one or both sides. The TM joints may be affected in rheumatoid arthritis.

\section{Investigations}

A computed tomography scan should be done if intracranial calcification or bleeding is suspected. Otherwise, magnetic resonance imaging is now generally considered the technique of choice not only due to concerns about the increased life-time risks of radiation induced malignancy from computed tomography, ${ }^{62}$ but also because of the broader range of information that can be obtained. The brain and cervical cord should be included in the study. Magnetic resonance angiography/ venography and gadolinium studies should be done if considered relevant. The cerebrospinal fluid pressure should be measured if abnormalities of intracranial/spinal pressure are being considered provided intracranial or high cervical structural lesions are excluded. Continuous pressure monitoring may be more helpful than an isolated measurement. 


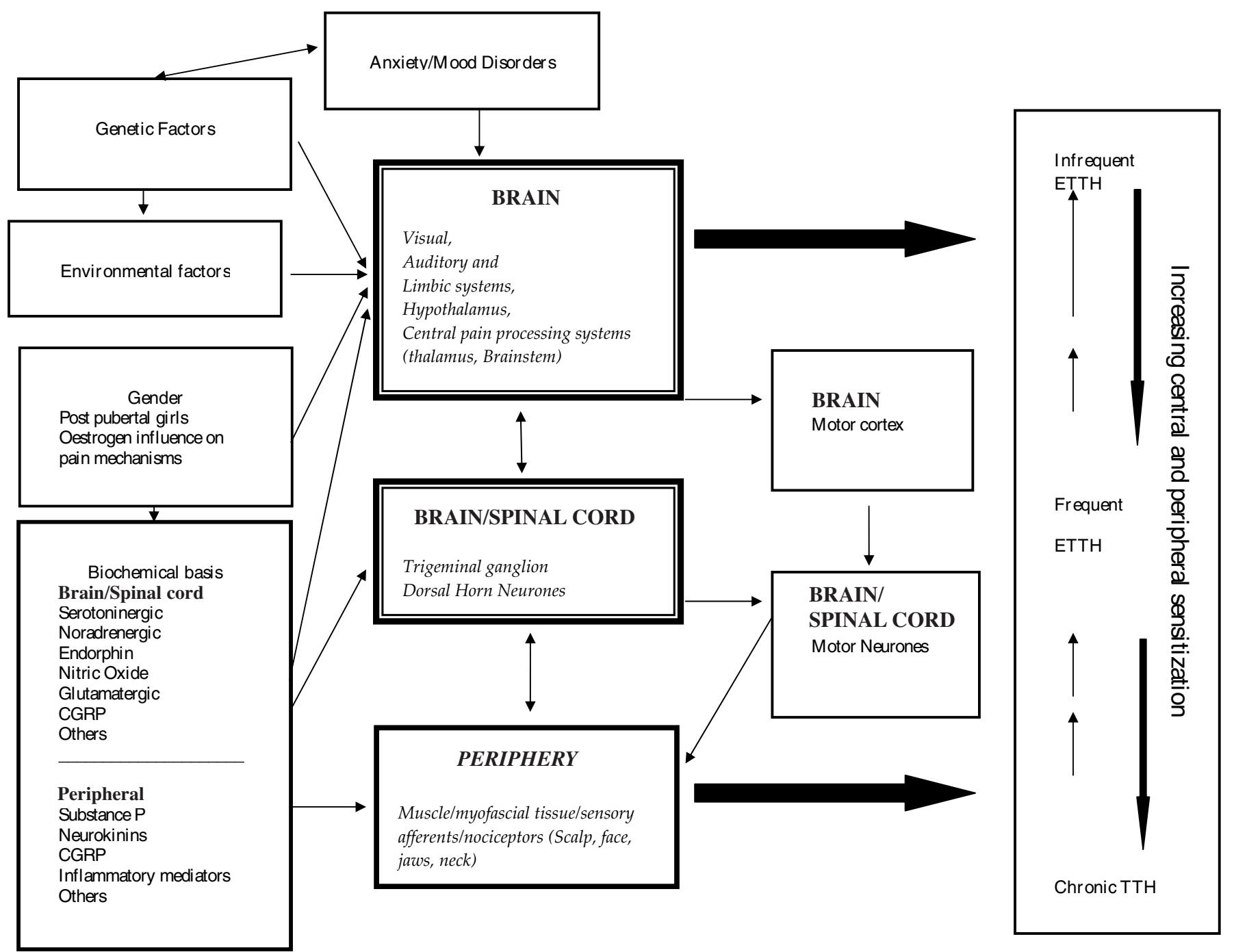

Figure: Possible neurobiological bases for and contributors to TTH. Environmental factors: Refer to non-genetic triggers such as stressors, light, sounds, smells, sleep deprivation, medication-overuse etc. CGRP: Calcitonin gene-related peptide; ETTH: episodic tension-type headache; CTTH: chronic tension-type headache; The bi-directional arrows connecting infrequent TTH to CTTH through frequent TTH are meant to show that the process can be reversed.

\section{Management}

\section{Basic}

1. Tension-type headache, like other types of primary headache in childhood, must be viewed from a multi-disciplinary bio-psychosocial perspective rather than a purely biomedical one. ${ }^{10,11,33,63-65}$ Multi-disciplinary management is essential when TTH is associated with significant stressors, anxiety or mood disorders. The management of stressors, anxiety and mood disorders often takes precedence over the pharmacologic management of headache; addressing them first also generally reduces headache severity.

2. Discussion of diagnosis and contributory factors. An information sheet helps to reinforce the discussion. Most parents and children are concerned about a serious intracranial cause, and reassurance about the absence of such causes can be therapeutic.

3. Emphasis on the importance of prospective charting of headache characteristics, illustrated with an example, and suggestions for identifying triggers.

4. Education on the proper use of analgesics, including avoidance of over-use. Children should not take analgesics more than three days a week.

5. Discussion on preventive/non-medication approaches to management. For example, noise on the school bus or during recess is often reported as a trigger; the use of ear plugs in this situation can be therapeutic as can the use of sun glasses if bright day light is a trigger. Sleep deprivation and over-use of products 
containing caffeine should be avoided. Massage, cold or hot packs can be helpful in individual patients.

6. Simple analgesics (acetaminophen or ibuprofen; aspirin if not contra-indicated in those $>15$ years-of-age) can be tried for the acute treatment of infrequent ETTH.

7. One must always re-assess the child to confirm the diagnosis.

8. The child must be involved in management discussions, and it is essential to interview children (especially teenagers) separately from caregivers.

\section{Specific}

The relatively high placebo effect in children, ${ }^{66}$ makes it difficult to assess the benefits of therapeutic efforts, pharmacologic or biobehavioral. Pharmacogenetic factors may influence drug effects.

\section{Medication Prophylaxis}

(i) The evidence for the benefit of any drug for TTH in children is low (level III or IV). However, their putative mechanisms of action on pain producing mechanisms make drugs such as amitryptiline, gabapentin, and topiramate worthy of trial. ${ }^{67-70}$ Their use is off-label. Doses are empiric and there are no studies that provide an evidence-base for doses calculated by body weight or surface area. Families should be told that benefit may not be apparent for two to three months. Treatment is continued for a three month headache free period before gradual withdrawal. Prophylaxis is usually offered for frequent ETTH and CTTH.

(ii) Amitryptiline, in relatively low doses, is generally the first choice for prophylaxis in TTH, including the 'mixed' type. The dose is increased by $5-10 \mathrm{mg}$ ( or $0.25 \mathrm{mg} / \mathrm{kg}$ ) every two to three weeks to a maximum of $1 \mathrm{mg} / \mathrm{kg} / \mathrm{day}$, based on headache frequency and severity. There are no randomized controlled trials. Grazzi et al compared amitryptiline (10mg/day) with 'relaxation training' in a small group of 19 and found both equally effective. ${ }^{71}$ We tend to start at $5-10 \mathrm{mg}$ ( or $0.25 \mathrm{mg} / \mathrm{kg}$ ) at dinner or bed time; the dose is increased by $5-10 \mathrm{mg}$ (or $0.25 \mathrm{mg} / \mathrm{kg}$ ) every two to three weeks to a maximum of $1 \mathrm{mg} / \mathrm{kg} /$ day based upon headache frequency, severity and presence or absence of side-effects. Doses exceeding $30 \mathrm{mg}$ at bedtime, even in those $>40 \mathrm{~kg}$, may be associated with daytime drowsiness or tiredness and diminishing therapeutic benefit. Weight gain is also a potential side-effect.

(iii) Topiramate and gabapentin. We are not aware of any studies on the use of these drugs for the prophylaxis of TTH in children. We favor gabapentin if rapid improvement is required (as for example in post concussion headache with TT features), as the dose can be escalated more rapidly than amitryptiline or topiramate. Doses range from $10-50 \mathrm{mg} / \mathrm{kg}$ in three to four divided doses. We have combined gabapentin and amitryptiline in severe cases. Topiramate is the preferred choice when subjects are overweight, and low doses $(25 \mathrm{mg}$ in two divided doses increased every two to three weeks by $12.5 \mathrm{mg}$ to a maximum of $100 \mathrm{mg} /$ day in two divided doses; on a body weight basis, approximately $0.25 \mathrm{mg} / \mathrm{kg} /$ day initially increased to a maximum of about $1 \mathrm{mg} / \mathrm{kg} /$ day) suffice.

(iii) Mirtazapine, a nor-epineprine-serotinin modulator, was found effective in the prophylaxis of CTTH in 24 subjects aged
18-65 years. ${ }^{72}$ We would avoid using this agent in children because of the risk of suicidal tendencies and absence of data in those $<18$ years-of-age.

(v) Magnesium pidolate (2.25 g twice daily for two months) was found effective in nine children with TTH in an open label study. ${ }^{73}$

(vi) Melatonin was reported to be effective for both migraine and TTH in children; however, the study was open label and the sample size very small. ${ }^{74}$ Placebo effect cannot be excluded.

(vii) It is doubtful if botulinum toxin type $\mathrm{A}$ is helpful in adults with TTH. ${ }^{75,76}$ There are no data in children.

\section{In-patient Management.}

This is reserved for those disabled by CTTH or frequent ETTH. Such admissions also permit us to observe the child and determine if the severity and disability (from headache) are concordant with their level of functioning on the ward. Additionally, one may be able to get a more reliable psychosocial history and observe interaction between child and family. Management principles, similar to those out-lined for adults, ${ }^{77}$ include: (i) avoid analgesics; (ii) consult psychologist and psychiatrist if this has not already been done; it may be necessary to involve a social worker if there are issues that need to be addressed at the school or home; (iii) in North America, a course of IV dihydroergotamine and metoclorpromide may be offered in such situations, a treatment based on observational data. ${ }^{78}$ Narcotics should be avoided.

\section{Bio-behavioral treatment.}

Antilla cites several references to suggest that electromyographic feedback combined with relaxation training can be used as an alternative to or in addition to pharmacotherapy. ${ }^{22}$ In a systematic review, Verhagen et al found 'conflicting' evidence for the effectiveness of relaxation therapy, and no evidence for or against the effectiveness of biofeedback or cognitive therapy in children with ETTH, although all these techniques were considered 'promising' ${ }^{79}$ Trautmann et al found psychologically based interventions to be effective in the management of migraine and TTH. ${ }^{80}$ Andrasik et al briefly discussed a short neurologist administered behavioral treatment. ${ }^{81}$ The authors of a Cochrane review found good evidence, 'that psychological treatments, principally relaxation and cognitive behavioral therapy, are effective in reducing the severity and frequency of chronic headache in children and adolescents'.82 These treatments have been discussed by Osterhaus, ${ }^{83}$ and given their efficacy should be offered as an alternative to pharmacological management for TTH.

\section{Other non-pharmacological treatments}

Lenssinck et al did not find any evidence for benefit from physiotherapy or spinal manipulation in adults with TTH. ${ }^{84}$ On the other hand, there is evidence for benefits from acupuncture for frequent ETTH and CTTH in adults. ${ }^{85}$ There are no comparable data in children.

Well designed studies are needed to assess the benefits of pharmacologic, psychological and other non-pharmacologic treatments for TTH in children. A multidisciplinary approach is essential for managing those with frequent ETTH and CTTH 
with children, families, pediatricians, child neurologists, psychiatrists and psychologists involved in planning care. ${ }^{10,11,33,54,63,64}$

Many aspects of adherence remain unexplored in those with TTH. These include appointment keeping and adherence to treatment regimes.

\section{Outcome}

Long-term data are limited. Studies on headache, including those published by one of us (SSS), have generally not stratified outcome by headache type, a limitation that must be rectified in future efforts. Information from three studies with follow-up periods ranging from 6 years to 20 years can be summarized as follows: (i) There was a 'considerable' shift from migraine to TTH and vice versa in $20 \%-25 \%$; (ii) considerable improvement occurred in $44 \%$ to $66 \%$; (iii) remission was more likely in males than females. ${ }^{12,31,32}$ The data suggest that a clinically significant number, females more than males, continue to have headache into adult life. Prospective studies on outcome from TTH, ideally into adult life and stratifying by gender and sub-type, are needed. Early treatment may minimize transformation from infrequent ETTH to CTTH.

\section{Conclusion}

Leviton, a renowned pediatric neurologist, argued against making the diagnosis of tension headache in children, suggesting that clinicians use migraine or benign headache of childhood instead; he felt that 'tension' had 'negative,' 'unfounded' and 'pejorative' connotations. ${ }^{86} \mathrm{We}$ strongly disagree with Leviton for several reasons: (i) TTH is an important primary headache disorder in children. The failure to accept TTH as an entity in its own right does injustice to the many who suffer from it; (ii) mislabeling TTH as migraine puts them at continuing risk for misdirected treatment; (iii) TTH is not always benign as many children will continue to have headaches into adulthood and (iv) finally, clinical and basic research to improve understanding and management will continue to languish. Tension-type headache in children deserves to be lifted from obscurity not condemned to continuing oblivion. The search for a more acceptable name can be part of this step.

\section{FOOT-Notes}

(i) Please consult the most current Pediatric Drug Dosage reference for doses of drugs discussed and for information about toxicity, drug interactions etc.

(ii) Central sensitization is defined as a state in which neurons (and related systems) subjected to (repeated) noxious stimuli become more sensitive to subsequent stimuli delivered to the receptive fields.

(iii) Peripheral sensitization is a similar phenomenon affecting peripheral nociceptors that transfer input from peripheral targets (skin, muscle, joints) though peripheral nerves to the central nervous system (spinal cord and brainstem).

As a consequence of either central or peripheral sensitization, stimuli that would normally not cause pain produce pain (allodynia). In addition, there may be an exaggerated and prolonged response (hyperalgesia).

\section{Disclosures}

Hershey: Grants or contract support from GlaxoSmithKline, Endo Pharmaceuticals, Boehringer-Ingelheim, MAP Pharma.

\section{ACKNOWLEDGEMENTS}

SSS thanks Drs. A.N. Prasad and M. Seshia for their reviews and suggestions. Presented (by SSS) at the CNSF 42nd Annual Congress: Headache Course, June 22, 2007.

\section{REFERENCES}

1. Headache Classification Subcommittee of the International headache society. The international classification of headache disorders. 2nd ed. Cephalalgia. 2004;24 Suppl 1:9-160.

2. Rasmussen BK, Jensen R, Schroll M, Olesen J. Epidemiology of headache in a general population--a prevalence study. J Clin Epidemiol. 1991;44(11):1147-57.

3. Bendtsen L, Jensen R. Tension-type headache: the most common, but also the most neglected, headache disorder. Curr Opin Neurol. 2006 Jun;19(3):305-9.

4. Jensen R, Bendtsen L. Tension-type headache: why does this condition have to fight for its recognition? Curr Pain Headache Rep. 2006 Dec;10(6):454-8.

5. Classification and diagnostic criteria for headache disorders, cranial neuralgias and facial pain. Headache classification committee of the International headache society. Cephalalgia. 1988;8 Suppl 7: 1-96.

6. Wober-Bingol C, Wober C, Karwautz A, Vesely C, WagnerEnnsgraber C, Amminger GP, et al. Diagnosis of headache in childhood and adolescence: a study in 437 patients. Cephalalgia. $1995 \mathrm{Feb} ; 15(1): 13-21$.

7. Abu-Arafeh I. Chronic tension-type headache in children and adolescents. Cephalalgia. 2001 Oct;21(8):830-6.

8. Rossi LN, Cortinovis I, Menegazzo L, Brunelli G, Bossi A, Macchi M. Classification criteria and distinction between migraine and tension-type headache in children. Dev Med Child Neurol. 2001 Jan;43(1):45-51.

9. Ozge A, Bugdayci R, Sasmaz T, Kaleagasi H, Kurt O, Karakelle A, et al. The sensitivity and specificity of the case definition criteria in diagnosis of headache: a school-based epidemiological study of 5562 children in Mersin. Cephalalgia. 2003 Mar;23(2): 138-45.

10. Balottin U, Nicoli F, Pitillo G, Ferrari Ginevra O, Borgatti R, Lanzi G. Migraine and tension headache in children under 6 years of age. Eur J Pain. 2004 Aug;8(4):307-14.

11. Balottin U, Termine C, Nicoli F, Quadrelli M, Ferrari-Ginevra O, Lanzi G. Idiopathic headache in children under six years of age: a follow-up study. Headache. 2005 Jun;45(6):705-15.

12. Kienbacher C, Wober C, Zesch HE, Hafferl-Gattermayer A, Posch M, Karwautz A, et al. Clinical features, classification and prognosis of migraine and tension-type headache in children and adolescents: A long-term follow-up study. Cephalalgia. $2006 \mathrm{Jul}$; 26(7):820-30.

13. Rossi LN, Vajani S, Cortinovis I, Spreafico F, Menegazzo L. Analysis of the international classification of headache disorders for diagnosis of migraine and tension-type headache in children. Dev Med Child Neurol. 2008 Apr;50(4):305-10.

14. Abu-Arafeh I. Classification of headache. Dev Med Child Neurol. $2008 \mathrm{Apr} ; 50(4): 246$

15. Seshia SS, Wolstein JR, Adams C, Booth FA, Reggin JD. International headache society criteria and childhood headache. Dev Med Child Neurol. 1994 May;36(5):419-28.

16. Seshia SS. Chronic daily headache in children and adolescents. Can J Neurol Sci. 2004 Aug;31(3):319-23.

17. Barea LM, Tannhauser M, Rotta NT. An epidemiologic study of headache among children and adolescents of Southern Brazil. Cephalalgia. 1996 Dec;16(8):545-9; discussion 523.

18. Anttila P, Metsahonkala L, Aromaa M, Sourander A, Salminen J, Helenius $\mathrm{H}$, et al. Determinants of tension-type headache in children. Cephalalgia. 2002 Jun;22(5):401-8. 
19. Ayatollahi SM, Moradi F, Ayatollahi SA. Prevalences of migraine and tension-type headache in adolescent girls of Shiraz (Southern Iran). Headache. 2002 Apr;42(4):287-90.

20. Laurell K, Larsson B, Eeg-Olofsson O. Prevalence of headache in Swedish schoolchildren, with a focus on tension-type headache. Cephalalgia. 2004 May;24(5):380-8.

21. Zwart JA, Dyb G, Holmen TL, Stovner LJ, Sand T. The prevalence of migraine and tension-type headaches among adolescents in Norway. the Nord-Trondelag health study (head-HUNT-youth), a large population-based epidemiological study. Cephalalgia. 2004 May;24(5):373-9.

22. Anttila P. Tension-type headache in childhood and adolescence. Lancet Neurol. 2006 Mar;5(3):268-74.

23. Unalp A, Dirik E, Kurul S. Prevalence and clinical findings of migraine and tension-type headache in adolescents. Pediatr Int. 2007 Dec;49(6):943-9.

24. Abu-Arefeh I, Russell G. Prevalence of headache and migraine in schoolchildren. BMJ. 1994 Sep 24;309(6957):765-9.

25. Seshia SS. Mixed migraine and tension-type: a common cause of recurrent headache in children. Can J Neurol Sci. 2004 Aug;31 (3):315-8

26. Waters WE. The epidemiological enigma of migraine. Int $\mathbf{J}$ Epidemiol. 1973;2(2):189-94.

27. Kaganov JA, Bakal DA, Dunn BE. The differential contribution of muscle contraction and migraine symptoms to problem headache in the general population. Headache. $1981 \mathrm{Jul}$;21(4):157-63.

28. Featherstone HJ. Migraine and muscle contraction headaches: a continuum. Headache. 1985 Jun;25(4):194-8.

29. Rasmussen BK, Jensen R, Olesen J. A population-based analysis of the diagnostic criteria of the international headache society. Cephalalgia. 1991 Jul;11(3):129-34.

30. Lipton RB, Stewart WF, Cady R, Hall C, O'Quinn S, Kuhn T, et al. Sumatriptan for the range of headaches in migraine sufferers: results of the Spectrum study. Headache. 2000 NovDec;40(10):783-91.

31. Guidetti V, Galli F. Evolution of headache in childhood and adolescence: an 8-year follow-up. Cephalalgia. 1998 Sep;18(7): 449-54.

32. Brna P, Dooley J, Gordon K, Dewan T. The prognosis of childhood headache: a 20-year follow-up. Arch Pediatr Adolesc Med. 2005 Dec;159(12):1157-60.

33. Seshia SS, Phillips DF, von Baeyer CL. Childhood chronic daily headache: a biopsychosocial perspective. Dev Med Child Neurol. 2008 Jul;50(7):541-5.

34. Russell MB, Levi N, Saltyte-Benth J, Fenger K. Tension-type headache in adolescents and adults: a population based study of 33,764 twins. Eur J Epidemiol. 2006;21(2):153-60.

35. Headache Classification Committee, Olesen J, Bousser MG, Diener HC, Dodick D, First M, Goadsby PJ, et al. New appendix criteria open for a broader concept of chronic migraine. Cephalalgia. 2006 Jun;26(6):742-6.

36. Russell MB, Ostergaard S, Bendtsen L, Olesen J. Familial occurrence of chronic tension-type headache. Cephalalgia. 1999 May;19(4):207-10.

37. Svensson DA, Larsson B, Bille B, Lichtenstein P. Genetic and environmental influences on recurrent headaches in eight to nine-year-old twins. Cephalalgia. 1999 Dec;19(10):866-72.

38. Ulrich V, Gervil M, Olesen J. The relative influence of environment and genes in episodic tension-type headache. Neurology. 2004 Jun 8;62(11):2065-9.

39. Russell MB, Levi N, Kaprio J. Genetics of tension-type headache: a population based twin study. Am J Med Genet B Neuropsychiatr Genet. 2007 Dec 5;144B(8):982-6.

40. Russell MB. Genetics of tension-type headache. J Headache Pain. 2007 Apr;8(2):71-6.

41. Marcus DA. Estrogen and chronic daily headache. Curr Pain Headache Rep. 2004 Feb;8(1):66-70.

42. Ashina S, Bendtsen L, Ashina M, Magerl W, Jensen R. Generalized hyperalgesia in patients with chronic tension-type headache. Cephalalgia. 2006 Aug;26(8):940-8

43. Lynch AM, Kashikar-Zuck S, Goldschneider KR, Jones BA. Sex and age differences in coping styles among children with chronic pain. J Pain Symptom Manage. 2007 Feb;33(2):208-16.
44. Jensen R. Pathophysiological mechanisms of tension-type headache: a review of epidemiological and experimental studies. Cephalalgia. 1999 Jul;19(6):602-21.

45. Bendtsen L. Central sensitization in tension-type headache-possible pathophysiological mechanisms. Cephalalgia. 2000 Jun;20(5):486-508.

46. Vandenheede M, Schoenen J. Central mechanisms in tension-type headaches. Curr Pain Headache Rep. 2002 Oct;6(5):392-400.

47. Ashina S, Bendtsen L, Ashina M. Pathophysiology of tension-type headache. Curr Pain Headache Rep. 2005 Dec;9(6):415-22.

48. Anttila P, Sourander A, Metsahonkala L, Aromaa M, Helenius H, Sillanpaa M. Psychiatric symptoms in children with primary headache. J Am Acad Child Adolesc Psychiatry. 2004 Apr;43(4):412-9.

49. Karwautz A, Wober C, Lang T, Bock A, Wagner-Ennsgraber C, Vesely $\mathrm{C}$, et al. Psychosocial factors in children and adolescents with migraine and tension-type headache: a controlled study and review of the literature. Cephalalgia. 1999 Jan;19(1):32-43.

50. Waldie KE. Childhood headache, stress in adolescence, and primary headache in young adulthood: a longitudinal cohort study. Headache. 2001 Jan;41(1):1-10.

51. Hershey AD, Powers SW, Vockell AL, LeCates S, Kabbouche MA, Maynard MK. PedMIDAS: development of a questionnaire to assess disability of migraines in children. Neurology. 2001 Dec 11;57(11):2034-9.

52. Powers SW, Patton SR, Hommel KA, Hershey AD. Quality of life in paediatric migraine: characterization of age-related effects using PedsQL 4.0. Cephalalgia. 2004 Feb;24(2):120-7.

53. Kernick D, Campbell J. Measuring the impact of headache in children: a critical review of the literature. Cephalalgia. 2009 Jan;29(1):3-16.

54. Abu-Arafeh I, Callaghan M. Headache clinics for children. In: AbuArafeh I, editor. Childhood headache. London: Clinics in Developmental Medicine No.158. Mac Keith Press; 2002. p. 175-88.

55. Hershey A, Kabbouche M, Powers S. Tension-type headache in the young. Curr Pain Headache Rep. 2006 Dec;10(6):467-70.

56. Abu-Arafeh I, Macleod S. Serious neurological disorders in children with chronic headache. Arch Dis Child. 2005 Sep;90 (9):937-40

57. Lewis DW, Ashwal S, Dahl G, Dorbad D, Hirtz D, Prensky A, et al. Practice parameter: evaluation of children and adolescents with recurrent headaches: report of the quality standards subcommittee of the American Academy of Neurology and the practice committee of the Child Neurology Society. Neurology. 2002 Aug 27;59(4):490-8.

58. Seshia SS. Specificity of IHS criteria in childhood headache. Headache. 1996 May;36(5):295-9.

59. Callaghan M, Abu-Arafeh I. Chronic posttraumatic headache in children and adolescents. Dev Med Child Neurol. 2001 Dec; 43(12):819-22.

60. Kirk C, Nagiub G, Abu-Arafeh I. Chronic post-traumatic headache after head injury in children and adolescents. Dev Med Child Neurol. 2008 Jun;50(6):422-5.

61. Senbil N, Gurer YK, Uner C, Barut Y. Sinusitis in children and adolescents with chronic or recurrent headache: a case-control study. J Headache Pain. 2008 Feb;9(1):33-6.

62. Brenner D, Elliston C, Hall E, Berdon W. Estimated risks of radiation-induced fatal cancer from pediatric CT. Am J Roentgenol. $2001 \mathrm{Feb}$;176(2):289-96.

63. Guidetti V, Galli F, Fabrizi P, Giannantoni AS, Napoli L, Bruni O, et al. Headache and psychiatric comorbidity: clinical aspects and outcome in an 8-year follow-up study. Cephalalgia. 1998 Sep;18(7):455-62.

64. Kabbouche MA, Powers SW, Vockell AL, LeCates SL, Ellinor PL, Segers A, et al. Outcome of a multidisciplinary approach to pediatric migraine at 1,2 , and 5 years. Headache. 2005 NovDec;45(10): 1298-303

65. Powers SW, Gilman DK, Hershey AD. Suggestions for a biopsychosocial approach to treating children and adolescents who present with headache. Headache. 2006 Oct;46 Suppl 3: S149-50. 
66. Lewis DW, Winner P, Wasiewski W. The placebo responder rate in children and adolescents. Headache. 2005 Mar;45(3):232-9.

67. Bendtsen L, Jensen R. Amitriptyline reduces myofascial tenderness in patients with chronic tension-type headache. Cephalalgia. 2000 Jul;20(6):603-10.

68. Hershey AD, Powers SW, Bentti AL, Degrauw TJ. Effectiveness of amitriptyline in the prophylactic management of childhood headaches. Headache. 2000 Jul-Aug;40(7):539-49.

69. Ashina S, Bendtsen L, Jensen R. Analgesic effect of amitriptyline in chronic tension-type headache is not directly related to serotonin reuptake inhibition. Pain. 2004 Mar;108(1-2):108-14.

70. Pappagallo M. Newer antiepileptic drugs: possible uses in the treatment of neuropathic pain and migraine. Clin Ther. 2003 Oct; 25(10):2506-38.

71. Grazzi L, Andrasik F, Usai S, D'Amico D, Bussone G. Pharmacological behavioural treatment for children and adolescents with tension-type headache: Preliminary data. Neurol Sci. 2004 Oct;25 Suppl 3:S270-1.

72. Bendtsen L, Jensen R. Mirtazapine is effective in the prophylactic treatment of chronic tension-type headache. Neurology. 2004 May 25;62(10): 1706-11.

73. Grazzi L, Andrasik F, Usai S, Bussone G. Magnesium as a treatment for paediatric tension-type headache: a clinical replication series. Neurol Sci. 2005 Feb;25(6):338-41.

74. Miano S, Parisi P, Pelliccia A, Luchetti A, Paolino MC, Villa MP. Melatonin to prevent migraine or tension-type headache in children. Neurol Sci. 2008 Sep;29(4):285-7.

75. Rozen D, Sharma J. Treatment of tension-type headache with botox: a review of the literature. Mt Sinai J Med. 2006 Jan; 73(1):493-8.

76. Evers S, Olesen J. Botulinum toxin in headache treatment: the end of the road? Cephalalgia. $2006 \mathrm{Jul} ; 26(7): 769-71$.

77. Freitag FG, Lake A,3rd, Lipton R, Cady R, Diamond S, Silberstein $\mathrm{S}$, et al. Inpatient treatment of headache: an evidence-based assessment. Headache. 2004 Apr;44(4):342-60.
78. Linder SL. Treatment of childhood headache with dihydroergotamine mesylate. Headache. 1994 Nov-Dec;34(10): 578-80.

79. Verhagen AP, Damen L, Berger MY, Passchier J, Merlijn V, Koes BW. Conservative treatments of children with episodic tensiontype headache. A systematic review. J Neurol. 2005 Oct;252(10): 1147-54.

80. Trautmann E, Lackschewitz H, Kroner-Herwig B. Psychological treatment of recurrent headache in children and adolescents--a meta-analysis. Cephalalgia. 2006 Dec;26(12):1411-26.

81. Andrasik F, Grazzi L, Usai S, D'Amico D, Leone M, Bussone G. Brief neurologist-administered behavioral treatment of pediatric episodic tension-type headache. Neurology. 2003 Apr 8;60(7): 1215-6.

82. Eccleston C, Palermo TM, Williams ACDC, Lewandowski A, Morley S. Psychological therapies for the management of chronic and recurrent pain in children and adolescents (Review). Cochrane Database Syst Rev. 2009, April 15; (2): CD003968.

83. Osterhaus S. Psychological treatment of paediatric headache. In: Abu-Arafeh I, editor. Childhood headache. London: Clinics in Developmental Medicine No.158. Mac Keith Press; 2002. p. 149-74.

84. Lenssinck ML, Damen L, Verhagen AP, Berger MY, Passchier J, Koes BW. The effectiveness of physiotherapy and manipulation in patients with tension-type headache: a systematic review. Pain. 2004 Dec;112(3):381-8

85. Linde K, Allais G, Brinkhaus B, Manheimer E, Vickers A, White AR. Acupuncture for tension-type headache. Cochrane Database Syst Rev. 2009 Jan 21;(1)(1):CD007587.

86. Leviton A. Even tension-type headaches doesn't sound right. Acta Paediatr. 2008 Oct;97(10):1344-5. 